RESEARCH REPORT

\title{
CORRELATION OF FLEXIBLE FLATFOOT AND Q-ANGLE AMONG SECONDARY SCHOOL STUDENTS BY USING DENNIS METHOD
}

\begin{abstract}
BACKGROUND AND AIMS

Flat foot has been reported as the most occurring clinical foot complication among pediatrics with more than $40 \%$ prevalence worldwide. This rate of prevalence is increasing by $21 \%$ to $57 \%$ in children aged 3-6 years respectively. Therefore, aim of this study is to determine the correlation between flexible flat foot and Q-angle among secondary school students by using Dennis method.
\end{abstract}

\section{METHODOLOGY}

This cross sectional study was conducted on 52 participants, aged 11-16 years. Screening of flat foot among participants was determined through navicular drop test. The jack toe rising test was also used to discriminate in flexible and rigid flat foot. The participants having flexible flat foot were then recruited and evaluated on Dennis method of flat foot grading.

\section{RESULTS}

The demographic characteristics of participants were represented through frequency, mean and standard deviation. Moreover, strong correlation between flat foot and Q-angle was observed on right side, whereas moderate correlation was detected on left side of flat foot respectively $(p<0.05)$.

\section{CONCLUSION}

It was concluded that flexible flat foot has strong association with Q-angle. However, future studies must be taken in to consideration for further assessment of flat foot.

\section{KEYWORDS}

Flat Foot, Quadriceps Muscles, Traumatic, Obesity, Knee Joint, Mechanics, Pediatrics

\author{
Hakim Ullah \\ Senior Lecturer \\ Ziauddin College of Rehabilitation \\ Sciences \\ Ziauddin University \\ hakimullah@zu.edu.pk
}

[Ullah H. Correlation of Flexible Flat Foot and Q-angle among Secondary School Students by using Dennis Method. Pak. J. Rehabil. 2019; 8(2): 44-49] 


\section{INTRODUCTION}

Flat foot, also known as fallen arches or pes planus is a postural deformity that results in a collapse of the foot arches.Flat foot has been reported as the most occurring clinical foot complication among pediatrics with more than $40 \%$ prevalence worldwide'. Although this rate of prevalence is increasing by $21 \%$ to $57 \%$ in children aged 3-6 years respectively ${ }^{2}$. In Pakistan, the prevalence of flexible flat foot in school going children is approximately $17 \%$ Majority of flat foot suffering children is 7 years of agelHowever, the prevalence for flat feet significantly diminishes with age ${ }^{2}$ such that infant born with flat feet is normal and medial longitudinal arch develops naturally by age 5-6 years ${ }^{3}$.

It is more common in males than females; moreover bilateral involvement is more frequent. The risk factors for flexible flat-foot include ligament laxity, male gender, young age, overweight, and obesity ${ }^{4}$. According to a study conducted in 2015 concluded that flexible flat foot is a critical part of foot evaluation as it is associated with adverse changes to the body due to structural deformity of lower extremity joint, change in muscle activity and decrease muscular strength and balance among children ${ }^{5}$. It was also claimed that flexible flat foot results in the stiffness of ankle dorsiflexors, asymmetric foot posture and associated locomotion difficulties that may results in balance deficits and motor control loss in children ${ }^{5-6}$. Another study reported that $30 \%$ of children have a calcanovalgus feet deformity which is not painful and may resolve on its own during the developmental stages ${ }^{7}$.

On the other hand, flexible flatfoot deformity differs from a rigid flat foot on the basis of the arch collapse that will be evident when the patient bears weight resulting in the re-appearance of a normal medial longitudinal arch in toe standing or with the ankle passively plantar flexed ${ }^{7}$. Moreover, the evaluation of either type of flat foot is based on the direct and indirect clinical approaches that may involve footprint measurements, anthropometric and radiographic techniques ${ }^{8}$. A recent survey conducted by Aenumulapalli et al in 2017 quantified flexible flat foot occurrence among children using a reliable and valid method i.e. the navicular drop test to determine the degree of flat foot by height of Medial Longitudinal Arch (MLA)' However, the results concluded that significant correlation between height and weight with Right Side Navicular Drop (RND) in comparison to left was found to be insignificant. It was also indicated that high percentage of flat feet leads to a reduction in the longitudinal arch that may resulted in the musculoskeletal disorders of lower limb as well as an impaired gait?. Recent studies have also shown the impact of flat foot on the Q-angle and its association with tibiofemoral mechanics i.e. a $Q$-angle of $>20^{\circ}$ imposes a risk of the patella getting pulled by the quadriceps muscles, increasing the chance of knee disorders ${ }^{8-10}$ In addition, the American Orthopedic
Association (AOA) considers $10^{\circ}$ to be normal and $15-20^{\circ}$ to be abnormal. Another study conducted in 2017 determined the relationship between Q-angle and flat foot among school going males revealed insignificant differences among subject's Q-angle between both their knees. It was also concluded that the presence of a flat foot deformity may also result in an increased Q-angle in the individual ${ }^{11}$. Consecutively, more evidences in this regard are needed to determine the associated factors imposed by the flat foot deformity. Therefore, the rationale of our study is to determine the correlation of flat foot and Q-angle by using Dennis method. This study will also serve as the basis of the clinical evaluation of the foot assessment and may predict the onset of associated risks related to deformity.

\section{METHODOLOGY}

\section{Study Design}

Cross-sectional Study

\section{Study Setting and Participants}

The study was conducted among secondary school students with flexible flat foot of Central District, Karachi.

\section{Duration of Study}

This study was completed for the duration of 6-8 months after approval of synopsis

\section{Sampling Technique}

Non-Probability Convenient Sampling Technique

\section{Sample Size}

Sample size was calculated by considering a study reference, conducted by Armin Abtahian MD in 2016 entitled as "A study of the prevalence of flatfoot in high school children". At 95\% Confidence Interval with bound of error $5 \%$, the calculated sample size was 52 .

\section{Inclusion Criteria}

- Students with flexible flat foot.

- Both boys and girls aged 11-16 years.

\section{Exclusion Criteria}

- Rigid Flat Foot.

- Knee Deformity ${ }^{12}$.

- Patellar Instability ${ }^{13}$.

- In-toe gait and Out-toe gait'14.

- Traumatic/surgical records.

\section{Data Collection Procedure}

Data was gathered based on the participant's physical characteristics, special tests and Dennis method of the right and left foot, respectively. At first, student's flat foot was diagnosed by using the Navicular Drop Test. A difference of $>10 \mathrm{~mm}$ was considered as positive test. After the diagnosis, students were assessed for flexible flat foot through Jack's toe-raising test. The test was performed while the patient in a weight bearing while clinician dorsiflexes the big toe 
and watched for an increasing concavity of medial longitudinal arch the foot. A positive result included the formation of arch on medial side of foot indicate a flexible flat foot whereas lack of arch formation indicate negative result in a rigid flat foot as shown in figure-1.

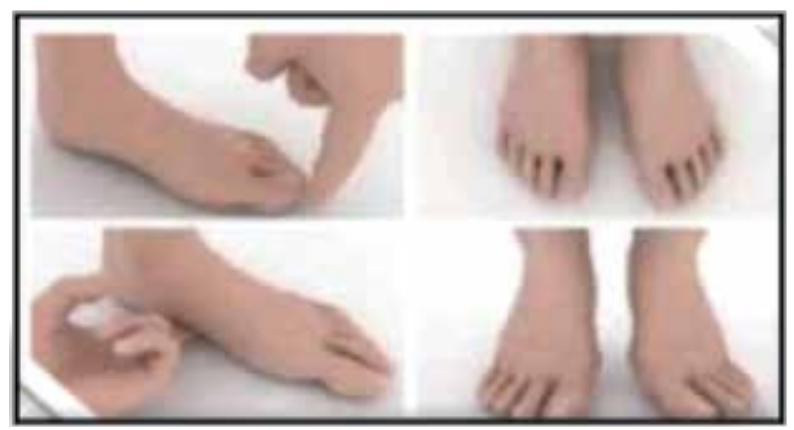

Figure.1 shows Jack Toe-rising Method

Afterwards, the students who had flexible flat foot were assessed through Dennis method. The foot print was determined by using photopodogram of each participant. The sole of foot was painted with paper developer liquid and then asked each participant to stand in a bipedal position on white paper on a smooth area. The sole of the foot is printed on the sheet. Accordingly, the diagnosis and the severity of the flexible flat foot will be assessed using the following grading of Dennis method as shown in figure-2.

- Grade-1: Central zone of forefoot support is half that of metatarsal support.

- Grade-2: Central zone of forefoot support is equal to metatarsal support.

- Grade-3: Central zone of the foot support is greater than width of the metatarsal support.

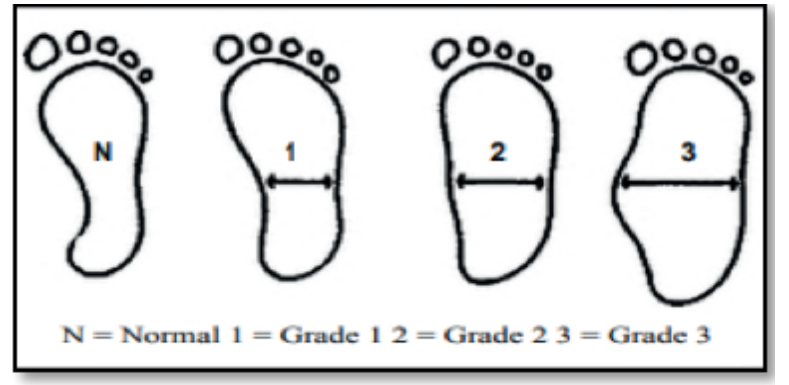

Figure.2 Dennis Method of Flat foot Grading

After the measurement of the grades of flat foot, the $Q$-angle of each participant will be assessed by drawing an imaginary

line between the anterior superior iliac spine to the mid of the patella while another line will be drawn between tibial tuberosity towards the mid of patella, the angle is formed and measure through goniometer such that to determine the correlation between the associated variables.

\section{Data Analysis}

Data entry and analysis was done on Statistical Package for Social Sciences (SPSS) version-20. Baseline characteristics were represented through mean, frequency and percentage chart. Further, Pearson correlation of coefficient was applied to assess the correlation between flatfoot and $Q$ angle.

\section{RESULTS}

A total of 52 participants recruited in the study consisted of 22 males and 30 females with mean age of $12.98 \pm 1.075$. Further, the demographic characteristics of participants including age in years (\%), prevalence of flexible flat foot, mean height, weight and Q-angle (Right and Left) is depicted in Table-1.

\begin{tabular}{|c|c|c|}
\hline $\begin{array}{l}\text { No. of } \\
\text { Participants }\end{array}$ & \multicolumn{2}{|c|}{52 (22 Males, 30 Females) } \\
\hline $\begin{array}{l}\text { Flexible } \\
\text { Flatfoot } \mathrm{n}(\%)\end{array}$ & \multicolumn{2}{|c|}{$52(20.8 \%)$} \\
\hline $\begin{array}{l}\text { Age } \\
\text { (Mean } \pm S . D)\end{array}$ & \multicolumn{2}{|c|}{$12.98 \pm 1.07$} \\
\hline Age in years (\%) & \multicolumn{2}{|c|}{$11(3 \%)$} \\
\hline & \multicolumn{2}{|c|}{$12(16 \%)$} \\
\hline & \multicolumn{2}{|c|}{$13(16 \%)$} \\
\hline & \multicolumn{2}{|c|}{$14(14 \%)$} \\
\hline & \multicolumn{2}{|c|}{$15(2 \%)$} \\
\hline & \multicolumn{2}{|c|}{$16(1 \%)$} \\
\hline Height & \multicolumn{2}{|c|}{$58.83 \pm 4.46$} \\
\hline Weight & \multicolumn{2}{|c|}{$48.34 \pm 10.74$} \\
\hline Q-angle & $\begin{array}{c}\text { Right Side } \\
18.65 \pm 1.32\end{array}$ & $\begin{array}{c}\text { Left Side } \\
18.84 \pm 1.10\end{array}$ \\
\hline
\end{tabular}

The non-parametric chi-square test of association was applied to determine the association between Q-angle and flat foot in right and left side respectively. The association was evaluated between the Dennis method of flat-foot grading and Q-angle that showed significant association $(p<0.05)$ of right flat foot. Similarly, strong association was found on between the left flat feet with Q-angle in all the Dennis grades as shown in table-2.

\begin{tabular}{|c|c|c|c|}
\hline \multicolumn{4}{|c|}{ Table.2 Chi-square Test of Association } \\
\hline \multicolumn{4}{|l|}{ Right Side } \\
\hline $\begin{array}{l}\text { Dennis } \\
\text { Method }\end{array}$ & $n$ & Chi-Square & *P -value \\
\hline Grade-1 & 20 & 14.40 & 0.002 \\
\hline Grade-2 & 20 & 10.80 & 0.013 \\
\hline Grade-3 & 12 & 11.33 & 0.010 \\
\hline \multicolumn{4}{|l|}{ Left Side } \\
\hline Grade-1 & 20 & 22.00 & 0.001 \\
\hline Grade-2 & 21 & 10.57 & 0.005 \\
\hline Grade-3 & 11 & 4.45 & 0.035 \\
\hline
\end{tabular}


Pearson correlation was run to determine the coefficient of correlation between flat foot and Q-angle. On right side, strong correlation is observed whereas moderate correlation was determined on left side of flat foot in relation to $Q$-angle as shown in Table-3.

\section{Table.3 Coefficient of Correlation between Q-angle and Flat-foot}

\begin{tabular}{|c|c|c|}
\hline Relationship between & r & *P-value \\
\hline Rt. Flat foot-Q-angle & 0.80 & $<0.05$ \\
\hline Lt. Flat foot -Q-angle & 0.50 & \\
\hline
\end{tabular}

\section{DISCUSSION}

The findings of our study showed that flexible flat foot have moderate to strong correlation with Q-angle. Although number of students have varying flat foot grades according to Dennis method of grading. Majority of studies has taken Q-angle in to consideration as an important clinical parameter that is shown to have substantial biomechanical effect on knee ${ }^{15}$. Recently, a study conducted by Raveendranath et al in 2019 stated that females have greater significance of $Q$-angle as compared to male as a result of greater lateral tibial tuberosity ${ }^{16}$. Recently, a study reported that females have been reported to have larger Q-angles in comparison to their male counterparts. However, according to a trigonometric evaluation conducted by Grelsamer et al a mean difference of $2.30^{\circ}$ degrees between the $\mathrm{Q}$-angles of males and females were reported. Furthermore, it was found that both the genders of equal height had established similar $Q$ angles ${ }^{17}$. Moreover, it was stated that $Q$-angle is a vital aspect for the positioning and movement of patella 15-16. It has also been anticipated that an increased in Q-angle may be related with an increased risk for knee injury since excessive lateral forces of knee could adversely influence the knee's mechanical alignment17. Recent studies demonstrated that the association between lower limb alignment and rate of injuries among athletes and recreational players showed that larger Q-angles are impactful in sustained knee injuries ${ }^{15-17}$. On the contrary, a number of studies reported that quadriceps contraction may cause alteration in Q-angle measurements, thus making it challenging to establish a direct connection between static Q-angle measurements and knee injury ${ }^{17}$. Moreover, certain studies also observed that Q-angle had negative correlation with height. It was also reported that $Q$-angle had negative association with height, length of lower limb and femurrespectively ${ }^{18}$. On the contrary, a study conducted by Grelsamer et al found significant association between the $Q$ angle and height. Besides, study suggested that with respect to age-adjusted, weight, pelvic-width, and gender the $Q$-angle decreases by $0.2^{\circ}$ degrees for each individual's centimeter of height ${ }^{18}$. Furthermore, another study compared the effect of lifestyle on Q-angle between male students and laborers. It was revealed that the mean $Q$-angle in laborers was less than in comparison with students. This difference could be due to varied quadriceps muscle tone, strength and morphology. Whereas, another study also compared Q-angle in individuals with sedentary lifestyle and soccer players reported that activities performed causes a change in quadriceps tone and strength that produced a remarkable effect on Q-angle resulting in decrease Q-angle ${ }^{18-20}$. However, limited researches have been conducted to investigate the association of $Q$-angle with flat foot, in particular to flexible type ${ }^{16-19}$. Shibuya et al (2010) stated that pes planus is a deformity that is considered by complete or partial loss of medial longitudinal arch that may leads to influence the skeletal maturity and other posture related difficulties. In this regard, our study found that flexible foot is common in school going adolescents ${ }^{11-16}$ years with varying grades on Dennis method with $8.7 \%$ prevalence. It has been speculated that these individuals may have poor posture or foot deformities with aging ${ }^{18}$. The findings are consistent with the study of Pourghasem et al that concluded that prevalence of flat foot was overall $16 \%$, although decrease with age. Moreover, the occurrence of flatfoot is highest among obese and overweight boys that are $(30.8 \%)^{19}$. Previous researches have used different methods to investigate the flat foot that has been expensive and non-reliable. Similarly, Sachini et al in assessed the asymptomatic flat foot among participants with navicular height and arch index as well as with AP and lateral radiographs ${ }^{20}$ whereas in our study; the flat foot among the participants was identified through navicular drop test while jack test was used to differentiate between rigid and flexible types of flat foot. Therefore, the screening of participants takes place by the use of reliable tools. Moreover, the measurement of $Q$-angle among participants was determined through goniometer similar to the study of Raveendranath et al that recorded the footprints of participants by Foot Print Mat and Staheli Arch Index. While some other author used three footprint measurements consisted of the Chippaux-Smirak Index (CSI), Clarke's Angle (CA), and Staheli Arch Index (AI), for relationship with clinical diagnosis with static foot prints of adolescents $^{21}$.Further, it was revealed that children having flat foot posture are more likely to have pain or discomfort at the back, hip and knee but the mechanisms of the proximal joint problems still remain unclear $^{21}$. In particular to our study, foot prints were recorded with Dennis Method Grading of flat foot. Moreover, our results showed that the Q-angle is strongly correlated with flat foot among young adults. To the best of author's knowledge, the study is the first to be conducted in Pakistan as it deter- 
mined that varying grades of flat foot. It was showed that most of participants have grade- 1 and grade-2 flat foot on right and left sides respectively while minimum number of participants lies in grade-3 flat foot. On contrary, study of Pourghasem et al revealed significant differences in flat foot grades among different age groups. Similar to our context, it was showed that grade- 1 and grade-2 flat foot were more prevalent in age 6-10 years while grade-3 was observed only in a 13-year-old girl. Consecutively, our study showed significantly strong correlation between Q-angle and flat foot on both right and left sides. While a comparative study conducted by Shih et al showed insignificant results of the correlation ${ }^{20-24}$.There are certain limitations encountered in this study that is small sample size. Also, numerous participants with unilateral or rigid flat foot have been excluded from the study that leads to sample constraint ${ }^{23}$. Therefore, large-scale studies with adequate sample size are recommended to investigate the relationship of Q-angle with flat foot, also multi-center trials should be directed to observe the response of related foot deformities ${ }^{23-25}$. Also, there were difficulties with participants schedule has been encountered, moreover lack of time and unidentified etiological factors also leads to observer bias in data collection ${ }^{24}$-Therefore, future studies must take all the aspects in to consideration to avoid such consequences related to the assessment of flat foot. Further, it is suggested that investigator must look out for the elements inflicting the flat foot and changes related to Q-angle. Despite, postural corrections and different body biomechanics should also be taken in consideration in future studies to govern the deformity at initial stage.

\section{CONCLUSION}

The study concluded fair to strong correlation is present between flatfoot Q-angle in right and left flatfoot respectively. Furthermore, large scale studies should be conducted among individuals of higher age group and larger scale areas for the early prevention of musculoskeletal disorders and structural deformities.

\section{REFRENCES}

[1] Ahmad A, Naz S, Zain A, Daud M. Prevalence of flat foot among children in schools of University Town Peshawar, Pakistan. RMJ. 2016:41 (4):465-6.

[2] Fung JP, Ismiarto YD, Mayasari W. Relationship between nutritional status and flat foot in children. Althea Med. J. $2017 ; 4(1): 152-6$.

[3] Askary Kachoosangy, R., Aliabadi, F. and Ghorbani, M. Prevalence of flat foot: comparison between male and female primary school students. Iran. Rehabil. J. 2013: 11 (2), pp.22-24.

[4] Yin J, Zhao H, Zhuang G, Liang X, Hu X, Zhu Y, Zhang $R$, Fan $X$, Cao Y. Flexible flatfoot of 6-13-year-old children: A cross-sectional study. J Orthop Sci. 2018 ;23(3):552-6.

[5] Um GM, Wang JS, Park SE. An analysis on muscle tone of lower limb muscles on flexible flat foot. J Phys Ther Sci. 2015;27(10):3089-92.

[6] Armin Abtahian MD, Farzan S. A study of the prevalence of flatfoot in high school children.Biomed. Res.2016:27(4)

[7] Halabchi F, Mazaheri R, Mirshahi M, Abbasian L. Pediatric flexible flatfoot; clinical aspects and algorithmic approach. Iran J Pediatr. 2013 ;23(3):247.

[8] Banwell HA, Paris ME, Mackintosh S, Williams CM. Paediatric flexible flat foot: how are we measuring it and are we getting it right? A systematic review. J Foot Ankle Surg 2018:;11(1):21.

[9] Aenumulapalli A, Kulkarni MM, Gandotra AR. Prevalence of flexible flat foot in adults: A cross-sectional study. J Clin Diagn Res2017: ; $11(6): A C 17$.

[10] Ebeye OA, Abade PO, Okwoka BO. Influence of gender on quadriceps (Q) angle among adult Urhobos in Nigeria population. Journal of Experimental and Clinical Anatomy. 2014;13(2):50.

[11] AlKhouli M.N , Ghait A.S, Abogazya A.A, Relationship between Flatfoot and $Q$ Angle in Male Secondary School Student: "Int. J. Physiother 2017: 5(6):2477-81.

[12] Filho FC, Luz BL, de Oliveira Trindade M, Garcia LC, Pinheiro ML, Garcia FC, Mendes MV. Epidemiological evaluation of genu valgum and flat feet in the child: experience of the martagão gesteira children's hospital.

[13] Lee TQ, Yang BY, Sandusky MD, McMahon PJ. The effects of tibial rotation on the patellofemoral joint: assessment of the changes in in situ strain in the peripatellar retinaculum and the patellofemoral contact pressures and areas. J. Rehabli. Research and development. 2014 38(5), 463-469.

[14] Abdel-aziem AA, Abdelraouf OR, El-Gohary TM. Effect of Body Position on Measurement of $Q$ Angle in Trained Individuals with and without Patellofemoral Pain. International Journal of Therapies and Rehabilitation Research. 2014;3(3):1.

[15] Tarawneh I, AL-Ajoulin O, Alkhawaldah A, Kalbouneh $H$, Hadidi $M$. Normal values of quadriceps angle and its correlation with anthropometric measures in a group of Jordanians. Jordan Med J. 2016;102(3396):1-6.

[16] Raveendranath R, Nachiket S, Sujatha N, Priya $R$, Rema D. Bilateral variability of the quadriceps angle ( $Q$ angle) in an adult indian population. Iran J Basic Med Sci. 2011; 14(5):465

[17] Teitge RA. Patellofemoral disorders: correction of rotational malalignment of the lower extremity. InNoyes' Knee Disorders: Surgery, Rehabilitation, Clinical Outcomes 2017 (pp. 1014-1035). Elsevier.

[18] Choudhary R, Malik M, Aslam A, Khurana D, Chauhan S. Effect of various parameters on 
Quadriceps angle in adult Indian population. Journal of clinical orthopedics and trauma. 201723.

[19] Shibuya N, Kitterman RT, LaFontaine J, Jupiter DC. Demographic, physical, and radiographic factors associated with functional flatfoot deformity. J Foot Ankle Surg. 2014;53(2):168-72.

[20] Pourghasem M, Kamali N, Farsi M, Soltanpour N. Prevalence of flatfoot among school students and its relationship with BMI. Acta Orthop Traumato.2016;50(5):554-7.

[21] Arachchige SN, Chander H, Knight A. Flat feet: Biomechanical implications, assessment and management. The Foot. 2019.

[22] Banwell HA, Paris ME, Mackintosh S, Williams CM. Paediatric flexible flat foot: how are we measuring it and are we getting it right? A systematic review. J Foot Ankle Res. 2018;11(1):21.

[23] Kothari A, Stebbins J, Zavatsky AB, Theologis T. Health-related quality of life in children with flexible flatfeet: a cross-sectional study. J Child Orthop. 2014:8(6):489-96

[24] Shih YF, Chen CY, Chen WY, Lin HC. Lower extremity kinematics in children with and without flexible flatfoot: a comparative study. BMC Musculoskelet Disord. $2012 ; 13(1): 31$.

[25] Elvan A, Simsek IE, Cakiroglu MA, Angin S. Association of quadriceps angle with plantar pressure distribution, navicular height and calcaneo-tibial angle. Acta orthopaedica et traumatologica turcica. 2019;53(2):145-9. 